\title{
PRESERVAÇÃO DO BAÇO NA PANCREATECTOMIA DISTAL POR TRAUMA
}

\author{
DISTAL PANCREATECTOMY WITH SPLENIC PRESERVATION \\ IN TRAUMATIC INJURIES OF PANCREAS
}

\author{
Wilson Luiz Abrantes, TCBC-MG ${ }^{1}$ \\ Roberto Carlos de Oliveira e Silva, TCBC-MG ${ }^{2}$ \\ Eliano Bonaccorsi Riani ${ }^{2}$ \\ Marco Aurélio Melo de Freitas ${ }^{3}$
}

\begin{abstract}
RESUMO: Objetivos: A esplenectomia simplifica a pancreatectomia distal no trauma mas tem o inconveniente de aumentar a vulnerabilidade do paciente às infecções. O objetivo é avaliar se a preservação do baço na referida cirurgia é exequiível e segura. Métodos: A preservação do baço foi feita em 52 pacientes $(48 \%)$ entre 108 submetidos à pancreatectomia distal. Quarenta e cinco (86,5\%) do sexo masculino e sete $(13,5 \%)$ do sexo feminino. Idade variou de seis a 42 anos com média de 22,1 anos. Trauma penetrante foi a causa da lesão em $35(67 \%)$ com $27(77 \%)$ por arma de fogo e oito (23\%) por arma branca. Contusão foi responsável pela lesão em 17 (33\%). Resultados: Não houve óbito. Fístula pancreática ocorreu em seis $(11,5 \%)$ pacientes; coleção subfrênica em seis (11,5\%); pancreatite em dois (3,8\%); abcesso de parede em quatro (8\%); pneumonia em quatro (8\%). Quarenta pacientes tiveram lesões associadas. O ISS médio foi de 19,3. O baço apresentava lesão em 13 pacientes. Sete foram submetidos à esplenorrafia e seis à ressecção parcial. Em 51 pacientes o baço foi conservado com os vasos esplênicos. Em um caso foi feita a ligadura proximal e distal dos vasos esplênicos (técnica Warschaw). Permanência hospitalar média de 12 dias. Conclusão: A pacreatectomia distal com preservação do baço mostrou ser segura nos pacientes estáveis, mesmo na presença de lesões associadas. A ausência de óbitos e a participação de cirurgiões em fase de treinamento confirmam sua segurança.
\end{abstract}

Descritores: Preservação baço; Pancreatectomia distal; Trauma pancreático.

\section{INTRODUÇÃO}

O baço é um órgão de grande importância imunológica e hematológica ${ }^{1,2}$. Sua remoção causa anormalidade imunológica, responsável pelas seguintes complicações: 1) maior predisposição à chamada infecção fulminante pósesplenectomia (IFPE) ${ }^{3}$; 2) aumento da morbidade precoce e tardia às infecções ${ }^{4} ; 3$ ) aumento da mortalidade séptica ${ }^{4}$. A IFPE é a complicação mais grave. Pode ocorrer em qualquer período da vida do esplenectomizado. Sua incidência varia de $0 \%$ a $1,5 \%$ mas causa $50 \%$ a $70 \%$ de óbito ${ }^{3}$. Estes conhecimentos estimularam a substituição da esplenecto- mia nas lesões traumáticas e na pancreatectomia distal (PD) pela preservação total ou parcial do órgão ${ }^{5,6}$. Nas lesões traumáticas a experiência acumulada é superior a quatro mil $\operatorname{casos}^{7}$. Na (PD) a preservação do baço foi feita pela primeira vez por Robey et al. em 1982. O tema despertou pouco entusiasmo e a revisão atual da literatura registra em torno de 150 casos, incluindo a presente série ${ }^{8-26}$. Complexidade do procedimento cirúrgico, aumento do tempo operatório, lesões associadas e baixa incidência das complicações pós-esplenectomia são os principais argumentos contrários a preservação. $O$ presente trabalho baseia-se no estudo de 52 pacientes operados sem óbito, no Hospital João XXIII.

1. Chefe do Serviço de Cirurgia do Hospital João XXIII

2. Cirurgião do Hospital João XXIII

3. Acadêmico de Medicina da Faculdade de Ciências Médicas

Recebido em 24/04/2001.

Aceito para publicação em 15/02/2002.

Trabalho realizado no Hospital João XXIII da Fundação Hospitalar do Estado de Minas Gerais (FHEMIG) 


\section{MÉTODO}

De janeiro de 1980 a dezembro de 1998 foram realizadas, no Hospital João XXIII, 108 pancreatectomias distais conseqüentes a lesões traumáticas de corpo e cauda do pâncreas. Em 52 pacientes (48\%) houve preservação do baço e constitui objeto do presente trabalho. Quarenta e cinco pacientes $(86,5 \%)$ eram do sexo masculino e sete $(13,5 \%)$ do sexo feminino. A idade variou de seis a 42 anos, com média de 22,1 anos. Trauma aberto ocorreu em 35 (67\%) com prevalência de arma de fogo, 27 (77\%) contra oito (23\%) por arma branca. Trauma fechado foi responsável por 17 (33\%). Seis pacientes (12\%) foram admitidos em estado de choque com resposta imediata à infusão de solução hidroeletrolítica. A indicação cirúrgica baseou-se na presença de sinais de irritação peritonial em $42(81 \%)$, ultra-som (US) nove casos (17\%) e tomografia computadorizada (TC) em um caso (2\%). A gravidade das lesões foi avaliada pelo Injury Severity Score (ISS). A maioria dos pacientes foi operada por cirurgiões em fase de treinamento - residentes do terceiro ano (R3).

Foi realizada laparotomia mediana ampla, com controle das lesões hemorrágicas e sutura das vísceras ocas lesadas. Acesso à retrocavidade dos epíplons e mobilização para a linha média do conjunto baço-pâncreas. Reconhecimento da lesão pancreática, identificação da artéria e veia esplênica e reparação das mesmas com um cadarço. Pontos de reparo na borda superior e inferior do pâncreas, $1 \mathrm{~cm}$ proximal ao ponto escolhido para secção da glândula. A manobra visa reduzir o sangramento. Secção da glândula, hemostasia, identificação do ducto da parte proximal e ligadura com fio inabsorvível e sutura oclusiva da extremidade proximal. A parte distal é cuidadosamente separada dos vasos esplênicos. A tração moderada, em sentido contrário à artéria esplênica e parênquima pancreático, facilita a identificação, ligadura e secção dos ramos colaterais. Idêntica manobra é feita em relação à veia esplênica (Figura 1). A manobra exige delicadeza. A ressecção do pâncreas pode ser feita também da cauda para o corpo (Figura 2). Revisão da hemostasia, proteção da superfície pancreática e dos vasos esplênicos com retalho do epíplon e drenagem (Figura 3).

\section{RESULTADOS}

Não houve óbito. Ocorreu fístula pancreática em seis $(11,5 \%)$, coleção subfrênica em seis $(11,5 \%)$, pancreatite em dois $(3,8 \%)$, abscesso de parede em quatro (8\%) e pneumonia em quatro (8\%). Quarenta pacientes (77\%) tiveram lesões associadas. Em 24 (46\%) houve mais de uma lesão (Tabela 1). O ISS variou de nove a 47, com média de 19,3. O tempo médio entre o trauma e a cirurgia foi de geralmente duas horas e 19 minutos. Em 51 pacientes o baço foi conservado com os vasos esplênicos. Em um paciente foi feita a ligadura proximal e distal dos vasos esplênicos (técnica Warschaw). Houve lesão do baço em 13 pacientes, dos quais sete foram tratados com sutura e seis com ressecção parcial. Permanência hospitalar média de 12 dias.

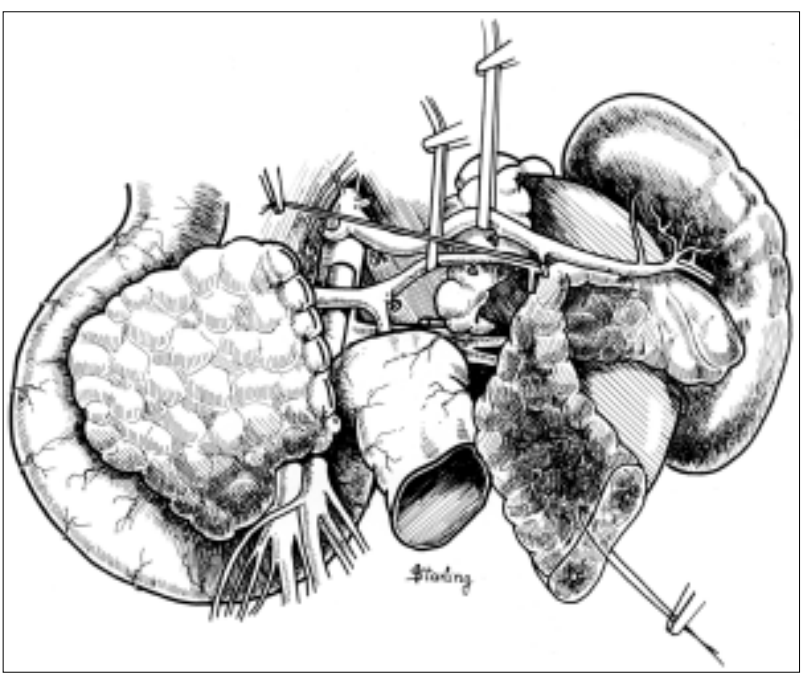

Figura $1-P D$ do corpo para a cauda. Sutura do pâncreas proximal e mobilização do segmento distal. (A leve tração, afastando o pâncreas dos vasos esplênicos, facilita a realização das ligaduras.)

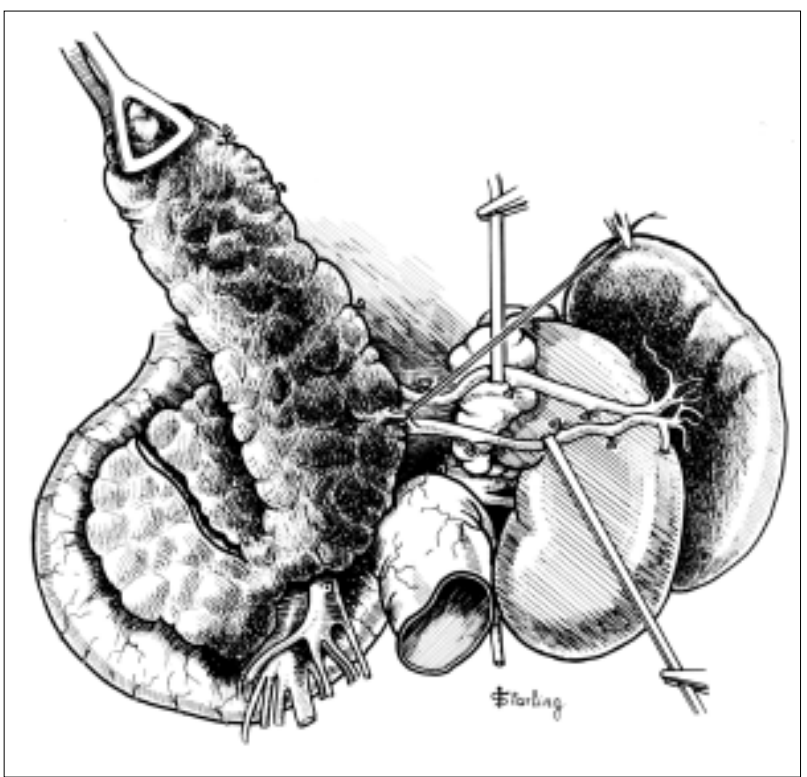

Figura $2-P D$ da cauda para o corpo.

\section{DISCUSSÃO}

A PD é a conduta mais segura de tratamento das lesões de corpo e cauda ${ }^{24,26}$. É indicada quando existe evidência ou suspeita de lesão ductal. A técnica foi sistematizada por Mallet-Guy 27 em 1936, com preservação do baço. A inclusão da esplenectomia à técnica original foi aceita porque, além de simplificar a ressecção pancreática, não havia na época nenhuma função atribuída ao baço. A comprovação clínica posterior de sua função imunológica estimulou a preservação parcial ou total do órgão inclusive na PD. Nestas situações, Pachter et $a l .{ }^{12} \mathrm{em}$ 


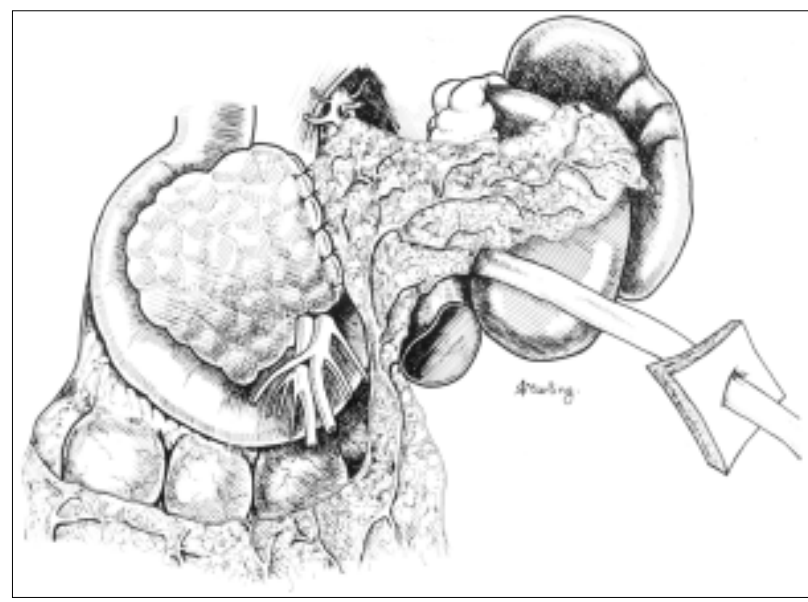

Figura 3 - Proteção dos vasos esplênicos e da superfície do pâncreas com retalho do epíplon. Drenagem da cavidade.

Tabela 1

Lesões associadas encontradas em 40 pacientes submetidos à pancreatectomia distal com preservação de baço

\begin{tabular}{ll}
\hline & $N^{o}$ \\
\hline Estômago & 15 \\
Rim & 12 \\
Baço & 12 \\
Fígado & 11 \\
Cólon & 08 \\
Intestino delgado & 07 \\
Duodeno & 03 \\
Vesícula & 01 \\
Diafragma & 06 \\
Uretra & 02 \\
\hline Total & 77 \\
\hline
\end{tabular}

1989 registraram 17 casos na literatura, nove de sua experiência pessoal. Concluem que a preservação do órgão é um procedimento seguro e possível de ser realizado com um mínimo de morbi-mortalidade. Cogbil et al. ${ }^{13} \mathrm{em}$ trabalho multicêntrico envolvendo nove centros de trauma estudaram 74 pacientes submetidos à PD. A preservação do baço foi realizada em 20 casos, sem óbito. O baço era normal em 17 casos e apresentava lesão em três, todos tratados com esplenorrafia. Do grupo total com baço normal $(n=32)$ houve preservação do órgão em 17 (53\%). Nenhum paciente apresentou hemorragia no pós-operatório. Contudo, três pacientes submetidos à PD com esplenectomia foram reoperados para controle de hemorragia no coto dos vasos esplênicos. A limitada experiência da literatura é consequiência da valorização excessiva dos argumentos contrários à preservação do órgão. De fato, para a maioria dos autores, o aumento de riscos de complicações provocadas pela complexidade da cirurgia e o prolongamento do tempo operatório não se justificam porque, na prática, a IFPE é uma complicação pouco freqüente. Acreditamos que a complexidade atribuída ao procedimento cirúrgico de preservação está relacionada com a falta de experiência com a técnica. A operação é simples, segura, exige paciência e delicadeza no manuseio das estruturas e está ao alcance do cirurgião geral. Quanto ao tempo cirúrgico, Richardson e Scoot-Conner ${ }^{18}$ realizaram estudos comparativos entre a PD com e sem esplenectomia concluindo que o aumento de tempo carece de significado estatístico. Por outro lado, a experiência comprova que em pacientes jovens e estáveis o aumento de tempo operatório não compromete a evolução pós-operatória. Na série, a média de tempo incluindo a correção de todas as lesões foi de três horas e 15 minutos. O tempo médio para a realização da PD foi 87 minutos. Finalmente, a baixa incidência IFPE seria um argumento convincente contra a preservação, se não fosse a invariável gravidade da complicação, a vulnerabilidade à mesma para o resto da vida e a simplicidade de sua profilaxia cirúrgica ${ }^{3,12}$. Está comprovado que o paciente esplenectomizado apresenta um aumento da morbidade e mortalidade séptica ${ }^{4}$. Este fato merece reflexão diante da gravidade atual de apresentação das infecções, resultante da seleção de bactérias por patógenos multirresistentes ${ }^{28}$. $\mathrm{Na}$ série, a preservação do baço foi realizada em seis pacientes após a estabilização hemodinâmica e em $40(77, \%)$ com lesões associadas dos quais 24 (46\%) com mais de uma lesão. A ausência de óbito na série e a participação de cirurgiões em fase de treinamento (R3) demonstram que o procedimento cirúrgico é simples e seguro, pode ser realizado na maioria dos pacientes mesmo na presença de lesões associadas e com baixa morbi-mortalida$\mathrm{de}^{12,13}$. A preservação do baço está contra-indicada nos pacientes instáveis que não respondem à infusão de líquidos e na presença de lesões associadas de correção complexa ou de evolução imprevisível (trauma cranioencefálico).

A preservação do órgão com seu pedículo vascular principal é a técnica mais empregada no trauma ${ }^{29}$. Foi utilizada em 51 casos da série (98\%) e 97\% da literatura. A presença de planos de clivagem, principalmente em crianças, facilita a liberação dos vasos esplênicos do tecido pancreático. A principal vantagem da técnica é garantir suprimento sangüíneo adequado ao baço. É a técnica de escolha quando simultaneamente é feita ressecção parcial do baço como ocorreu em dois casos da série. De fato, estudos sugerem que quando a irrigação do baço residual é feita pela artéria principal seu desempenho imunológico parece mais eficaz ${ }^{29}$. Em outra técnica (técnica de Warshaw) é feita a ligadura proximal e distal dos vasos esplênicos evitando a dissecção dos mesmos do tecido pancreático. A nutrição do baço é feita pelos vasos gástricos curtos, embora haja relato de necrose do órgão ${ }^{30,31}$. A incidência de fístula e outras complicações é semelhante à relatada na literatura ${ }^{12,13,31}$. Os resultados demonstram que a PD com preservação do baço é um procedimento seguro nos pacientes estáveis, mesmo na presença de lesões associadas. As vantagens da preservação do órgão são expressas por Pachter ${ }^{12}$. 


\begin{abstract}
Objectives: Splenectomy simplifies distal pancreatectomy in trauma but has the inconvenience of increasing vulnerability to infection. The objective of this study is to assess whether spleen preservation in the aforementioned surgical procedure is feasible and safe. Methods: Spleen preservation was performed in 52 patients (48\%) of 108 undergoing distal pancreatectomy. Forty-five (86.5\%) were males and 7 (13,5\%) were females. The mean age was 22.1 years, varying from 6 to 42 years. Penetrating trauma was the cause of injury in 35 cases (67\%), 27 of which $(77 \%)$ due to gunshot wounds and $8(23 \%)$ due to stab wounds. Blunt trauma was the cause of injury in 17 cases (33\%). Results: There were no deaths. Pancreatic leaks occurred in 6 (11.5\%) patients, fluid collection in the splenic fossa in 6 (11.5\%), pancreatitis in $2(3.8 \%)$, surgical wound abscesses in $4(8 \%)$ and pneumonia in 4 (8\%) patients. Forty patients had associated injuries. The average ISS was 19.3. The spleen was injured in 13 patients. Seven underwent splenorrhaphy and 6 required partial splenic resection. The spleen and splenic vessels were preserved in 51 patients. In one case, proximal and distal ligation of the splenic vessels (Warschaw technique) was performed. Hospital stay averaged 12 days. Conclusion: Distal pancreatectomy with spleen preservation was shown to be a safe procedure in stable patients, even with associated injuries. The absence of deaths and the co-participation of surgeons in training confirms the safety of this procedure.
\end{abstract}

Key Words: Splenic preservation; Distal pancreatectomy; Pancreatic trauma

\title{
REFERÊNCIAS
}

1. Shaw JFN, Print CG. Postsplenectomy sepsis. Br J Surg, 1989, 76:1074-1081.

2. Pimpl W, Dapunt O, Kaindl H, Thalmer J. Incidence of septic and thromboembolic - related diaths after splenectomy in adults. Br J Surg, 1989, 76:517-521.

3. Di Cataldo A, Puleo S, Li Destri G et al. Splenic trauma and overwhelming postsplenectomy infection. Br J Surg, 1987, 74:443 - 445

4. Green JB, Shackford SR, Sise MJ et al. Late septic complications in adults fallowing splenectomy for trauma. A prospective analysis of 144 patients. J Trauma, 1986, 26:999-1004.

5. Abrantes WL, Lucena MS, Scholobach M. Cirurgia conservadora do trauma esplênico. Rev Ass Med Bras, 1994 40:113-117.

6. Rabelo GD, Abrantes WL, Drumond DAF. Esplenectomia versus cirurgia conservadora do trauma esplênico. Rev Col Bras Cir, 1991, 18:80-86.

7. Campos Christo M, Didio LJA. Anatomical and surgical of splenic segmentectomies.Ann Anat, 1997, 179:461474.

8. Robey E, Mulleu JT, Schwab CV. Blunt transection of the pancreas treated by distal pancreatectomy splenic salvagen and hiperalimentation - Four cases review of the literature. Ann Surg, 1982, 196:695-699.

9. Dawson DL,Scott-Conner CEH. Distal pancreatectomy with splenic preservation. The anatomy basic for a meticulous operation. J Trauma, 1986, 26:1142-1145.

10. Civil ID, D’Malley KF, Schwab CW. Tissue sparing distal pancreatectomy. Surg Rounds, 1987, 10:29-39.

11. Richardson DQ, Scott-Conner CEH. Distal pancreatectomy with and without splenectomy - A comparative study. Am J Surgeon, 1989, 55:21-25.

12. Pachter HL, Hofstter SR, Liang HG, Hobballah J. Traumatic injuries of pancreas. The role of the pancreatectomy with splenic preservation. J Trauma, 1991, 29:1352-1355.
13. Cogbil TH, Moore EE, Morris Jr. JH et al. Distal pancreatectomy for trauma. A multicenter experience. J Trauma, 1991, 31:1600-1604.

14. Shein M, Freinkel W, D`Egidio A. Splenic conservation in distal pancreatic injury. Stay away fron hilum (letter to the editor). J Trauma, 1991, 31:431.

15. Aldridge MC, Willianson RCV. Distal pancreatectomy with and without splenectomy. Br J Surg, 1991, 98:976979.

16. Pradere B, Julio $\mathrm{CH}$, Rimailho J et al. Pancreatectomies gauches awec conservation de la rate sans pedicule. A propos de troise. Anna Chr, 1992, 46-620-624.

17. Yvatur RR, Simon RJ, Grignard J et al. The spleen at risk after penetrating trauma. J Trauma, 1993, 35:409414.

18. Sheridan R, Mithell J. Blun pancreatic transection: management by distal pancreatectomy with splenic salvage. Injury, 1994 25:677-678.

19. Sriussadaporn S. Management of pancreatic injuries. J Med Assoc Tail, 1994, 77:580-587.

20. MeGahren ED, Magnusou D, Shaller RT, Tapper D. Management of transected pancreas in children. Aust NZ J Surg, 1995, 65:242-246.

21. Farrel RS, Krige JEJ, Bornman PC et al. Operative stategies in pancreatic trauma. Br J Surg, 1996, 83:934937.

22. Steinman E, Utiyama EM, Fugita OT et al. Ferimentos pancreáticos. Rev Col Bras Cir, 1992, 19:126-132.

23. Babian TC, Kennet HA Kudsk MD et al. Superiority of closed suction drainage for pancreatic traumatic. A randonized prospective study. Ann Surg 1990, 211:724730.

24. Rasslan S, Casaroli AA, Abrantes WA et al. Pancreatectomia distal no trauma. Estudo multicêntrico. Rev Col Bras, 1998, 25:409-414

25. Jobst MA, Canty TG, Linch FP. Management of pancreas injury in pediatric blunt abdominal trauma. J Ped Surg, $1999,34: 818-824$ 
26. Abrantes WL, Silva RCO. Preservatión del bazo en la pancreatectomia distal por trauma en el niño. Rev Cir Inf, 1999, 220(3):283- 296.

27. Mallet-Guy P, Rachon A. Pancreatitis chroniques gauches Paris - Masson \& Ed., 1943.

28. Weistein RH, Hayden MK. Multiply resistant pathogens: Epidemiology and control. In: Bennett JV, Brachman PS. Hospital Infections. Fourth Ed Lippicolt, Raven, 1998:215-236.

29. Scher KS, Scott-Conner C, Jones CW, Wroczynsky F. Methods of splenic preservation and their effect on clearance of pneumococcal bacteremia.Ann Surg, 1985 202:595-599.

30. Warshaw AL. Conservation of the spleen with distal pancreatectomy. Arch Surg, 1988, 123:550-553.
31. Shein M, Freinkel W, D'Egidio A. Splenic conservation in distal pancreatic injury. Stay away fron hilum (Letter to the editor) J Trauma, 1991, 31:431.

Endereço para correspondência:

Dr. Wilson Luiz Abrantes

Rua Mondovi, 133

31340-590 — Belo Horizonte-MG 